\title{
Resposta de cultivares de arroz de sequeiro ao preparo do solo e à irrigação por aspersão(1)
}

\author{
Orivaldo Arf ${ }^{(2)}$, Ricardo Antônio Ferreira Rodrigues ${ }^{(3)}$, Marco Eustáquio de Sá(2) \\ e Carlos Alexandre Costa Crusciol(4)
}

\begin{abstract}
Resumo - O presente trabalho teve o objetivo de avaliar o comportamento de cultivares de arroz de sequeiro em diferentes modalidades de preparo de solo e lâminas de água aplicadas por aspersão, no Município de Selvíria, MS. Os tratamentos consistiram na combinação de três cultivares de arroz (IAC 201, Carajás e Guarani), três sistemas de preparo do solo (arado de aiveca + grade niveladora, escarificador + grade niveladora e grade pesada + grade niveladora) e três níveis de irrigação por aspersão (sequeiro e duas lâminas de água), com quatro repetições. O uso da irrigação por aspersão reduziu o número de dias para o florescimento e o ciclo da cultura. A cultivar Carajás apresentou a maior produtividade de grãos e praticamente ausência de acamamento em relação às cultivares IAC $201 \mathrm{e}$ Guarani. O preparo do solo com arado de aiveca e escarificador propiciaram a obtenção de maior produtividade de grãos em relação ao preparo com grade aradora em ano com presença de veranico, e as duas lâminas de água promoveram incrementos de $113 \%$ e $177 \%$ na produção de grãos, em ano com ocorrência de veranico.
\end{abstract}

Termos para indexação: arado de aiveca, grades, discos, retenção de água no solo, níveis de irrigação.

\section{Performance of dryland rice cultivars in function of soil preparation systems and sprinkler irrigation}

\begin{abstract}
The present paper had the objective to evaluate the performance of dryland rice cultivars in different soil preparation systems and water deep applied through sprinkler, in Selvíria County, MS, Brazil. Treatments consisted of combination of three rice cultivars (IAC 201, Carajás and Guarani), three soil preparation systems (moldboard plow + disking, chisel + disking, and disk harrow + disking) and three levels of irrigation by sprinkler (zero and two water deeps), with four replications. The use of irrigation by sprinkler reduced the number of days to full flowering and the cycle of crop. The Carajás cultivar presented the largest grain production and practically absence of lodging in comparison to IAC 201 and Guarani. Soil preparation with moldboard plow and chisel provided the largest grain production in relation to other preparation systems, in moisture stress condition. The two water deeps increased the grain production in $113 \%$ and $177 \%$, respectively, in the year with moisture stress.
\end{abstract}

Index terms: mouldboard ploughs, harrows, disks, soil water retention, irrigation rates.

\section{Introdução}

O arroz constitui fonte importante de calorias e de proteínas na dieta alimentar do povo brasileiro. En-

(1)Aceito para publicação em 25 de julho de 2000 .

Parcialmente financiado pela FAPESP e CNPq.

(2)Universidade Estadual Paulista (UNESP), FE, Dep. de Fitotecnia, Economia e Sociologia Rural, Caixa Postal 31, CEP 15385-000 Ilha Solteira, SP.

E-mail: gd@adm.feis.unesp.br

(3)UNESP, FE, Dep. de Ciência do Solo e Engenharia Rural

(4)UNESP, FCA, Dep. de Agricultura e Melhoramento Vegetal. tretanto, a produção deste cereal tem oscilado de ano para ano, e eventualmente não tem sido suficiente para atender o consumo interno, resultando na necessidade de importação do produto. Uma das alternativas para atender a demanda de consumo interno é o aumento da produtividade da cultura, o que pode ser alcançado com a utilização da irrigação por aspersão. A estabilidade de produção proporcionada pelo uso da irrigação por aspersão estimula o uso de práticas de maior nível tecnológico, com conseqüente aumento na produtividade.

No que se refere ao consumo de água pela cultura do arroz, de acordo com Brunini et al. (1981) e Carva- 
lho Júnior (1987), 30\% é consumido durante a fase vegetativa, 55\% durante a fase reprodutiva, e 15\%, na fase de maturação. Deficiências hídricas simuladas pela supressão da irrigação, em casa de vegetação, no início da emissão das panículas, com duração de quatro a oito dias, provocaram reduções da ordem de 60 a $87 \%$, respectivamente, na produtividade de grãos (Stone et al., 1986).

O aumento da produtividade, pelo uso da irrigação por aspersão, além de ser influenciado pela precipitação pluvial no período de cultivo, varia com a cultivar utilizada. Assim, Santos (1990) e Oliveira (1994) obtiveram maiores incrementos na produtividade do arroz com a utilização da irrigação suplementar por aspersão, em comparação com o cultivo no sistema de sequeiro.

Estudos desenvolvidos por Crusciol (1995) no Município de Selvíria, MS, mostraram que a deficiência hídrica na fase vegetativa prolonga o ciclo do arroz; o uso da irrigação por aspersão até a tensão de água no solo, de $0,035 \mathrm{MPa}$, provocou acamamento de aproximadamente $15 \%$ das plantas; a densidade de 100 sementes viáveis por metro quadrado é a mais indicada para a cultivar de arroz IAC 201, quando cultivada em condições de sequeiro e de irrigação por aspersão até a tensão de água no solo de -0,035 MPa; e o espaçamento de $30 \mathrm{~cm}$ entre fileiras da cultivar IAC 201 proporcionou melhor produtividade de grãos, em cultivo irrigado por aspersão na tensão de água no solo até -0,035 MPa, ou em condições de sequeiro sob alta precipitação pluvial.

Nakao (1995), também no Município de Selvíria, MS, verificou que o aumento na lâmina de água causa aumento na altura das plantas e no grau de acamamento; a cultivar Carajás apresenta maior produtividade que a IAC 201, sendo de 3.992 e $3.474 \mathrm{~kg} \mathrm{ha}^{-1}$, respectivamente; a irrigação incrementa a produção de grãos das duas cultivares utilizadas, ficando mais evidente na IAC 201.

A produção das culturas depende do fornecimento de quantidades adequadas de água. O armazenamento temporário da água no solo é importante porque permite menor freqüência de irrigação. Naturalmente, não se deve esperar que solos sob cultivo mantenham as características físicas e químicas originais, mas deve-se procurar manejá-los de modo a alterar o mínimo possível estas características, espe- cialmente as que afetam a infiltração e retenção de água, como a porosidade e a agregação (Castro et al., 1987).

De acordo com Pedroso \& Corsini (1983), no preparo convencional do solo as operações são realizadas continuamente numa mesma profundidade, podendo ocasionar em alguns tipos de solo uma camada compactada resultante da pressão do arado como também da grade sobre o solo, conhecidas como péde-arado e pé-de-grade. O efeito imediato da compactação é a redução do volume de macroporos, que afeta a difusão da água e dos gases e dificulta o desenvolvimento das raízes das plantas.

Estudando vários métodos de preparo de solo, Seguy et al. (1985), citados por Kluthcouski et al. (1988), verificaram que o enraizamento do arroz de sequeiro aumentou em $26 \%$ no perfil de 0 a $60 \mathrm{~cm}$, quando o solo sofreu descompactação nos primeiros $30 \mathrm{~cm}$. Observaram, ainda, que no preparo superficial contínuo, ou seja, compactado, $85 \%$ das raízes encontravam-se nos primeiros $10 \mathrm{~cm}$, enquanto no solo descompactado foram observados apenas $51 \%$ do total.

De acordo com Oliveira et al. (1996), um período de deficiência hídrica moderada ocasionou decréscimos de $13,7 \%$ na produção de grãos e de $14,7 \%$ na de matéria seca do arroz de sequeiro. O preparo profundo do solo com arado de aiveca minimizou o efeito da deficiência hídrica, ocasionando aumentos de $28,4 \%$ na produção de grãos e de $23,9 \%$ na produção de matéria seca. Este resultado indica que, em situação de deficiência hídrica moderada (10 a 15 dias de estiagem), um preparo do solo bem feito é capaz de substituir com vantagens a irrigação suplementar.

O presente trabalho teve como objetivo avaliar o comportamento das cultivares de arroz de sequeiro IAC 201, Carajás e Guarani, cultivadas em diferentes modalidades de preparo de solo e lâminas de água aplicadas por aspersão, no Município de Selvíria, MS.

\section{Material e Métodos}

O trabalho foi conduzido nos anos agrícolas de 1997/98 e 1998/99, em área experimental da Faculdade de Engenharia de Ilha Solteira, UNESP, no Município de Selvíria, MS, situado a $51^{\circ} 22^{\prime}$ de longitude Oeste e $20^{\circ} 22^{\prime}$ de latitude Sul, com altitude de $335 \mathrm{~m}$. O solo do local é do 
tipo Latossolo Vermelho-Escuro, epi-eutrófico álico, textura argilosa. A precipitação média anual é de $1.370 \mathrm{~mm}$, a temperatura média anual é de $23,5^{\circ} \mathrm{C}$, e a umidade relativa do ar média anual entre $70 \%$ e $80 \%$.

Antes da instalação do experimento foram coletadas amostras de solo da área experimental na profundidade de 0,0 a $0,20 \mathrm{~m}$ e realizada a análise química para fins de fertilidade, de acordo com o método proposto por Raij \& Quaggio (1983), apresentando os seguintes resultados: $\mathrm{pH}\left(\mathrm{CaCl}_{2}\right) 5,8 ; 22 \mathrm{~g} \mathrm{~kg}^{-1}$ de M.O.; $15 \mathrm{mg} \mathrm{dm}^{-3}$ de $\mathrm{P}$ (resina); 1, 34, 12 e $20 \mathrm{mmol}_{\mathrm{c}} \mathrm{dm}^{-3} \mathrm{de} \mathrm{K}, \mathrm{Ca}, \mathrm{Mg} \mathrm{e} \mathrm{H}+\mathrm{Al}$, respectivamente, e $70 \%$ de saturação por bases.

A capacidade de retenção de água no solo foi determinada utilizando-se uma unidade de sucção segundo Grohmann (1960) na faixa de 0,002 a 0,01 MPa, aparelhos de pressão de placa porosa recomendados por Richards \& Fireman (1943), na faixa de 0,033 a $0,101 \mathrm{MPa}$, e a membrana de Richards (1947), na faixa de 0,101 a 1,52 MPa.

O delineamento experimental utilizado foi o de blocos casualizados, com um esquema fatorial $3 \times 3 \times 3$, totalizando 27 tratamentos constituídos pela combinação de três cultivares de arroz de sequeiro (IAC 201, Carajás e Guarani), com três sistemas de preparo do solo (escarificador + grade niveladora, arado de aiveca + grade niveladora e grade pesada + grade niveladora) e três níveis de irrigação por aspersão (não-irrigado, lâmina 1 e lâmina 2), com quatro repetições.

As parcelas foram constituídas por sete linhas de $6 \mathrm{~m}$ de comprimento, com espaços de $0,40 \mathrm{~m}$ entre si, totalizando uma área de $16,8 \mathrm{~m}^{2}$, sendo a área útil constituída pelas cinco linhas centrais, desprezando-se $0,5 \mathrm{~m} \mathrm{em}$ ambas as extremidades de cada linha. Deixou-se um espaço livre de $6 \mathrm{~m}$ entre as parcelas.

As cultivares IAC 201, Carajás e Guarani apresentam ciclo curto e são recomendadas para cultivo de sequeiro no Estado de Mato Grosso do Sul (Bazoni et al., 1995). Nas condições edafoclimáticas do Município de Selvíria, MS, as cultivares tem apresentado praticamente o mesmo número de dias da emergência ao florescimento e da emergência à colheita (Oliveira, 1994; Nakao, 1995; Arf et al., 2000). As cultivares IAC 201 e Carajás apresentam comportamento contrastante quanto à resposta à irrigação por aspersão (Oliveira, 1994).

Nos tratamentos irrigados, o fornecimento de água foi realizado por meio de um sistema fixo de irrigação convencional por aspersão com precipitação de $3,3 \mathrm{~mm}$ hora $^{-1}$ nos aspersores. A precipitação pluvial foi determinada em um pluviômetro Ville de Paris, instalado na área experimental.

A evaporação de água (ECA) foi obtida diariamente do tanque classe A instalado no posto agrometeorológico da área experimental. O coeficiente do tanque classe $\mathrm{A}(\mathrm{Kp})$ utilizado foi o proposto por Doorenbos \& Pruitt (1976), sendo que este é função da área circundante, velocidade do vento e umidade relativa do ar.

Quanto aos coeficientes da cultura $(\mathrm{Kc})$, estes foram diferentes para os períodos que sucederam a emergência, levando-se em consideração o valor máximo do $\mathrm{Kc}=1,0$, referente ao período total de crescimento (Doorenbos \& Kassan, 1979). A lâmina 1 de água consistiu na utilização de três coeficientes de cultura $(\mathrm{Kc})$, distribuídos em quatro períodos compreendidos entre a emergência e a colheita. $\mathrm{Na}$ fase vegetativa, foi utilizado um valor de 0,2 , na fase reprodutiva dois coeficientes de cultura $(\mathrm{Kc})$, o inicial de 0,35 , e o final, de 0,50 e na fase de maturação, os mesmos coeficientes, invertendo os valores. A lâmina 2 de água foi caracterizada por utilizar o dobro dos valores de $\mathrm{Kc}$ nos mesmos períodos da lâmina 1, e o cultivo sem irrigação contou somente com a água proveniente da chuva. O controle da irrigação foi feito inicialmente com a capacidade de armazenamento de água disponível máxima $(16,8 \mathrm{~mm})$, subtraindo-se sucessivamente o valor da evapotranspiração máxima até que o total de água atingia o valor da água disponível do solo $(10 \mathrm{~mm})$.

O preparo do solo, dependendo do tratamento, foi realizado por meio de escarificador, arado de aiveca ou grade aradora e duas gradagens niveladoras, sendo a segunda gradagem niveladora realizada às vésperas da semeadura.

Após a abertura mecanizada dos sulcos realizou-se manualmente a adubação básica com $250 \mathrm{~kg} \mathrm{ha}^{-1}$ da fórmula $8-28-16+0,5 \% \mathrm{Zn}+0,3 \%$ de B. No cálculo da quantidade de fertilizante, foram levadas em consideração as características químicas do solo, a produtividade esperada, e as recomendações de Raij et al. (1996). Aplicou-se o inseticida granulado carbofuran $\left(1.500 \mathrm{~g} \mathrm{ha}^{-1}\right.$ de i.a. $)$ no sulco, fazendo-se, então, a semeadura manual (7/11/97 e 5/11/98), com o número de sementes necessário para obter um estande ao redor de 120 plantas $\mathrm{m}^{-2}$. Após a cobertura das sementes com uma camada de 4 a $5 \mathrm{~cm}$ de terra, aplicou-se o herbicida em pré-emergência oxadiazon (1.000 $\mathrm{g} \mathrm{ha}^{-1}$ de i.a.). Aos 39 dias após a emergência das plantas, realizou-se a adubação de cobertura com $30 \mathrm{~kg} \mathrm{ha}^{-1}$ de N, na forma de sulfato de amônio.

Quando aproximadamente $90 \%$ das panículas apresentavam grãos com coloração típica de maduros, realizou-se a colheita das linhas centrais, manualmente. Em seguida, foi realizada a secagem ao sol, durante um a dois dias, e posteriormente, a trilha mecânica em trilhadeira de parcela.

No presente trabalho foram realizadas as seguintes avaliações: emergência das plântulas; número de dias transcorridos entre a semeadura e a emergência da maioria das plântulas (ponto de agulhamento); floração e ciclo: núme- 
ro de dias transcorridos entre a emergência e a floração de $50 \%$ das plantas das parcelas, e o número de dias transcorridos entre a emergência e a maturação de $90 \%$ das panículas da parcela; altura das plantas: distância média $(\mathrm{cm})$ compreendida desde a superfície do solo até a extremidade superior da panícula mais alta, determinada em 10 plantas ao acaso, na área de cada parcela, durante o estádio de grãos até a forma pastosa; grau de acamamento: obtido através de observações visuais na fase de maturação, utilizando-se a seguinte escala de notas: 0 : sem acamamento; 1: até 5\%; 2: 5 a 25\%; 3: 25 a 50\%; 4: 50 a 75\%; 5: 75 a $100 \%$ de plantas acamadas; número de panículas por metro quadrado: número de panículas contidas em 1,0 $\mathrm{m}$ de fileira de plantas na área útil das parcelas, posteriormente convertido a número de panículas $\mathrm{m}^{-2}$; massa de 100 grãos: pesagem de duas amostras coletadas ao acaso de 100 grãos de cada parcela (13\% base úmida); produção de grãos: pesagem dos grãos em casca, provenientes da área útil das parcelas, corrigindo-se a umidade para $13 \%$ e convertendo em kg ha-1 ; peso hectolítrico: determinado em balança especial para peso hectolítrico com teor de água dos grãos corrigidos para $13 \%$ (base úmida), utilizando-se duas amostras por parcela.

\section{Resultados e Discussão}

No ano agrícola 1997/98 houve menor precipitação mensal, a partir do mês de dezembro, do que no ano agrícola 1998/99 (Figura 1). O período de florescimento no primeiro ano de cultivo ocorreu de 22 a 31 de janeiro nos tratamentos irrigados, e de 2 a
6 de fevereiro no tratamento de sequeiro, período esse de baixa precipitação e também agravado pela falta de água no período de 3 a 11 dias antes do florescimento, onde a planta apresenta maior suscetibilidade à falta de água. O florescimento no segundo ano de cultivo ocorreu de 21 a 26 de janeiro em todos os tratamentos, e no período de maior sensibilidade, antes do florescimento, houve boa disponibilidade de água para a cultura.

Cultivares IAC 201, Carajás e Guarani apresentaram, dentro de cada parâmetro estudado (preparo do solo ou lâmina de água), número de dias para florescimento e ciclo muito próximos, concordando com Oliveira (1994), Nakao (1995) e Arf et al. (2000) (Tabela 1). A variação no número de dias para florescimento e colheita ocorreu principalmente em função das lâminas de água. Onde não foi utilizada a irrigação, os tratamentos apresentaram maior número de dias para florescimento e colheita, principalmente no primeiro ano de cultivo (1997/98), em razão da quantidade e distribuição de chuvas, que foi inferior ao segundo ano de cultivo (1998/99). Os resultados concordam com os obtidos por Crusciol (1995), que verificou que a deficiência hídrica na fase vegetativa prolonga o ciclo do arroz.

Quanto à altura das plantas, observa-se que houve efeito significativo para cultivares, preparo do solo e lâminas de água no primeiro ano de cultivo (1997/98) (Tabela 2). Já no segundo ano (1998/99), houve efeito significativo apenas para cultivares.

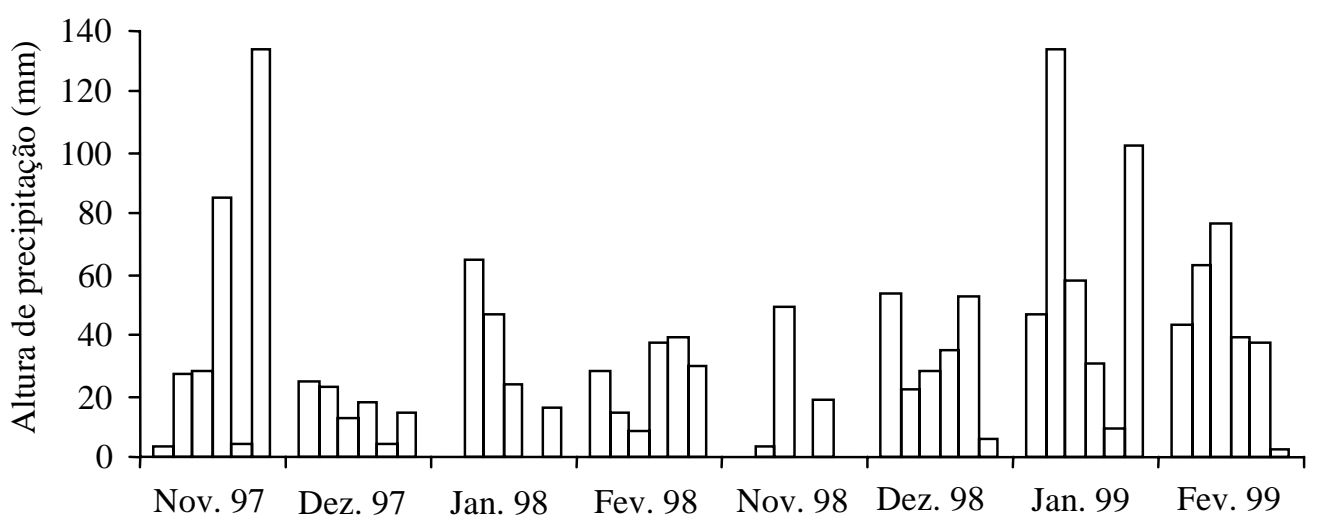

Meses

Figura 1. Pluviometria $(\mathrm{mm})$ registrada em qüinqüídeos, durante a condução do experimento nos anos de 1997/98 e 1998/99. 
Tabela 1. Número de dias para florescimento e ciclo após a emergência das plântulas de cultivares de arroz em resposta a diferentes tipos de preparo do solo e de irrigação por aspersão. Selvíria, MS, 1997/98 e 1998/99(1).

\begin{tabular}{|c|c|c|c|c|c|c|c|c|c|c|c|c|}
\hline \multirow{4}{*}{$\begin{array}{l}\text { Preparo do } \\
\text { solo }\end{array}$} & \multicolumn{12}{|c|}{ Irrigação } \\
\hline & \multicolumn{4}{|c|}{ Sem irrigação } & \multicolumn{4}{|c|}{ Lâmina 1} & \multicolumn{4}{|c|}{ Lâmina 2} \\
\hline & \multicolumn{2}{|c|}{ Florescimento } & \multicolumn{2}{|c|}{ Ciclo } & \multicolumn{2}{|c|}{ Florescimento } & \multicolumn{2}{|c|}{ Ciclo } & \multicolumn{2}{|c|}{ Florescimento } & \multicolumn{2}{|c|}{ Ciclo } \\
\hline & $97 / 98$ & 98/99 & $97 / 98$ & 98/99 & $97 / 98$ & 98/99 & $97 / 98$ & $98 / 99$ & $97 / 98$ & $98 / 99$ & $97 / 98$ & $98 / 99$ \\
\hline & \multicolumn{12}{|c|}{ IAC 201} \\
\hline Aiveca & 83 & 76 & 118 & 101 & 77 & 73 & 101 & 101 & 72 & 75 & 99 & 101 \\
\hline Escarificador & 82 & 76 & 118 & 101 & 77 & 73 & 99 & 101 & 71 & 73 & 99 & 101 \\
\hline \multirow[t]{2}{*}{ Grade } & 86 & 75 & 118 & 101 & 80 & 75 & 104 & 101 & 74 & 73 & 99 & 101 \\
\hline & \multicolumn{12}{|c|}{ Carajás } \\
\hline Aiveca & 84 & 74 & 123 & 101 & 78 & 73 & 103 & 101 & 74 & 72 & 99 & 101 \\
\hline Escarificador & 83 & 74 & 118 & 101 & 78 & 73 & 101 & 101 & 72 & 71 & 99 & 101 \\
\hline \multirow[t]{2}{*}{ Grade } & 86 & 74 & 120 & 101 & 81 & 73 & 105 & 101 & 77 & 72 & 102 & 101 \\
\hline & \multicolumn{12}{|c|}{ Guarani } \\
\hline Aiveca & 82 & 72 & 118 & 101 & 77 & 72 & 101 & 101 & 73 & 72 & 99 & 101 \\
\hline Escarificador & 83 & 73 & 118 & 101 & 77 & 71 & 99 & 101 & 71 & 71 & 99 & 101 \\
\hline Grade & 85 & 73 & 118 & 101 & 79 & 71 & 103 & 101 & 76 & 71 & 103 & 101 \\
\hline
\end{tabular}

(1)Lâmina 1: na fase vegetativa foi utilizado o coeficiente de cultura $(\mathrm{Kc})$ de 0,2 ; na fase reprodutiva foi utilizado um $\mathrm{Kc}$ inicial de 0,35 e final de 0,50 , e na fase de maturação, um Kc inicial de 0,50 e final de 0,35 ; lâmina 2 : foi utilizado o dobro dos valores de Kc para os mesmos períodos da lâmina 1 .

Tabela 2. Valores médios obtidos na avaliação da altura de planta, acamamento e número de panículas $\mathrm{m}^{-2}$ de cultivares de arroz de terras altas em resposta a diferentes sistemas de preparos do solo e lâminas de água aplicadas através de irrigação por aspersão. Selvíria, MS, 1997/98 e 1998/99(1).

\begin{tabular}{|c|c|c|c|c|c|c|}
\hline \multirow[t]{2}{*}{ Tratamento } & \multicolumn{2}{|c|}{$\begin{array}{l}\text { Altura da planta } \\
(\mathrm{cm})\end{array}$} & \multicolumn{2}{|c|}{$\begin{array}{c}\text { Acamamento } \\
\text { (notas) }^{(1)}\end{array}$} & \multicolumn{2}{|c|}{$\begin{array}{c}\text { Panículas } \\
\text { (número } \mathrm{m}^{-2} \text { ) }\end{array}$} \\
\hline & $97 / 98$ & 98/99 & 97/98 & 98/99 & 97/98 & 98/99 \\
\hline \multicolumn{7}{|l|}{ Cultivar } \\
\hline IAC 201 & $106,50 \mathrm{~b}$ & $95,58 \mathrm{c}$ & 1,76 & $1,01 \mathrm{~b}$ & $71,92 b$ & $65,75 b$ \\
\hline Carajás & $105,89 b$ & $101,39 b$ & 0,08 & $0,30 \mathrm{c}$ & $85,00 \mathrm{a}$ & $77,89 \mathrm{a}$ \\
\hline Guarani & $110,17 \mathrm{a}$ & $118,17 \mathrm{a}$ & 2,24 & $3,69 \mathrm{a}$ & $81,56 \mathrm{a}$ & $74,42 \mathrm{a}$ \\
\hline \multicolumn{7}{|l|}{ Preparo do solo } \\
\hline Aiveca & $111,28 \mathrm{a}$ & 107,31 & 1,49 & 1,42 & 82,58 & 72,58 \\
\hline Escarificador & $108,61 \mathrm{a}$ & 104,53 & 1,67 & 1,63 & 79,42 & 72,97 \\
\hline Grade & $102,67 b$ & 103,31 & 0,58 & 1,25 & 76,47 & 72,50 \\
\hline \multicolumn{7}{|l|}{$\overline{\text { Irrigação }^{(2)}}$} \\
\hline Sem irrigação & $97,58 \mathrm{c}$ & 105,69 & 0,36 & 1,45 & $76,47 \mathrm{~b}$ & 74,31 \\
\hline Lâmina 1 & $108,94 b$ & 106,83 & 1,33 & 1,53 & $78,47 \mathrm{ab}$ & 73,22 \\
\hline Lâmina 2 & $116,03 \mathrm{a}$ & 102,61 & 2,19 & 1,31 & $83,53 \mathrm{a}$ & 70,53 \\
\hline \multicolumn{7}{|l|}{ Teste F } \\
\hline Cultivar (C) & $5,31 * *$ & $84.81 * *$ & $60.62 * *$ & $107.03 * *$ & $13,25 * *$ & $13.75 * *$ \\
\hline Preparo do solo $(\mathrm{P})$ & $19,28 * *$ & $2,59^{\mathrm{ns}}$ & $14,93 * *$ & $1,44^{\mathrm{ns}}$ & $2,69^{\mathrm{ns}}$ & $0,02^{\mathrm{ns}}$ \\
\hline Lâminas de água (L) & $85,90 * *$ & $2,94^{\mathrm{ns}}$ & $34,12 * *$ & $0,48^{\mathrm{ns}}$ & $3,81 *$ & $1,33^{\mathrm{ns}}$ \\
\hline $\mathrm{C} \times \mathrm{P}$ & $0,81^{\mathrm{ns}}$ & $1,71^{\mathrm{ns}}$ & $2,65 *$ & $1,08^{\mathrm{ns}}$ & $0,92^{\mathrm{ns}}$ & $1,44^{\mathrm{ns}}$ \\
\hline $\mathrm{C} \times \mathrm{L}$ & $0,55^{\mathrm{ns}}$ & $0,24^{\mathrm{ns}}$ & $5,79 * *$ & $0,04^{\mathrm{ns}}$ & $0,66^{\mathrm{ns}}$ & $0,98^{\mathrm{ns}}$ \\
\hline $\mathrm{P} \times \mathrm{L}$ & $0,78^{\mathrm{ns}}$ & $1,84^{\mathrm{ns}}$ & $2,47 *$ & $1,69^{\mathrm{ns}}$ & $0,86^{\mathrm{ns}}$ & $0,69^{\mathrm{ns}}$ \\
\hline $\mathrm{C} \times \mathrm{P} \times \mathrm{L}$ & $0,65^{\mathrm{ns}}$ & $0,36^{\mathrm{ns}}$ & $1,34^{\mathrm{ns}}$ & $0,14^{\mathrm{ns}}$ & $0,85^{\mathrm{ns}}$ & $0,75^{\mathrm{ns}}$ \\
\hline C.V. (\%) & 5,60 & 7,27 & 28,08 & 24,75 & 14,06 & 13,92 \\
\hline
\end{tabular}

(1)Médias seguidas de mesma letra dentro de cada parâmetro (cultivar, preparo do solo e lâmina de água) não diferem entre si pelo teste de Tukey a 5\% de probabilidade; em acamamento, a análise refere-se aos dados transformados em $\sqrt{\mathrm{x}+0,5} ;$ notas de acamamento: 0 : sem acamamento; 1 : até $5 \% \cdot 2 \cdot 5$ a $25 \% ; 3: 25$ a $50 \% ; 4: 50$ a 75\%; 5: 75 a $100 \%$ de plantas acamadas. ${ }^{(2)}$ Lâmina 1 : na fase vegetativa foi utilizado o coeficiente de cultura (Kc) de 0,$2 ;$ na fase reprodutiva foi utilizado um Kc inicial de 0,35 e final de 0,50 ; e na fase de maturação, um Kc inicial de 0,50 e final de 0,35 ; lâmina 2: foi utilizado

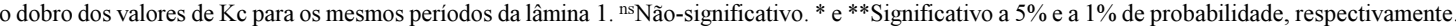


A cultivar Guarani se destacou das demais, apresentando altura das plantas superior a $110 \mathrm{~cm}$, nos dois anos de experimentação. No primeiro ano de cultivo, o preparo do solo com grade aradora propiciou a obtenção de plantas mais baixas do que o preparo realizado com arado de aiveca e escarificador. O tratamento sem irrigação apresentou a menor altura de plantas, e a lâmina 2 apresentou o maior desenvolvimento das plantas, concordando com Nakao (1995), que também obteve aumento na altura das plantas com o aumento nas lâminas de água.

Quanto ao acamamento das plantas, no primeiro ano de cultivo houve efeito significativo para cultivar, preparo do solo, lâminas de água e das interações cultivar x preparo do solo, cultivar x lâminas de água e preparo do solo x lâminas de água, enquanto no segundo ano (1998/99) houve apenas efeito significativo para cultivares, onde a cultivar Guarani apresentou maior grau de acamamento (50 a $75 \%$ de plantas acamadas) seguida pela IAC 201 e Carajás ( 1 a $5 \%$ de plantas acamadas) (Tabela 2). Os desdobramentos das interações significativas da análise de variância referente ao primeiro ano de cultivo (1997/98) estão apresentados nas Tabelas 3 e 4. A cultivar Carajás apresentou o menor grau de acamamento nas diferentes modalidades de preparo do solo e as cultivares IAC 201 e Guarani, apresentaram o menor grau de acamamento no preparo realizado com grade aradora (Tabela 3). Na ausência de irrigação, a cultivar Carajás e a IAC 201 apresentaram o menor grau de acamamento, e a cultivar Carajás praticamente nenhum acamamento nas diferentes lâminas de água utilizadas (Tabela 4). A cultivar IAC 201 apresentou menor acamamento no tratamento sem

Tabela 3. Desdobramento da interação cultivar x preparo do solo da análise de variância referente ao acamamento de $\operatorname{plantas}^{(1)}$.

\begin{tabular}{llcl}
\hline Cultivar & \multicolumn{3}{c}{ Preparo do solo } \\
\cline { 2 - 4 } & Aiveca & Escarificador & Grade \\
\hline IAC 201 & $2,08 \mathrm{aA}$ & $2,70 \mathrm{aA}$ & $0,74 \mathrm{aB}$ \\
Carajás & $0,06 \mathrm{~b}$ & $0,20 \mathrm{~b}$ & $0,00 \mathrm{~b}$ \\
Guarani & $3,00 \mathrm{aA}$ & $2,74 \mathrm{aA}$ & $0,17 \mathrm{aB}$ \\
\hline
\end{tabular}

(1) Médias seguidas de letras diferentes, minúsculas nas colunas e maiúsculas nas linhas, diferem entre si, pelo teste de Tukey a $5 \%$ de probabilidade; notas de acamamento: 0 : sem acamamento; 1: até $5 \% ; 2: 5$ a $25 \% ; 3: 25$ a $50 \%$; $4: 50$ a $75 \%$; $5: 75$ a $100 \%$ de plantas acamadas irrigação, comparativamente aos tratamentos irrigados. Já a cultivar Guarani, apresentou acamamento crescente do tratamento não-irrigado ao tratamento lâmina 2. Arf(1993) também observou que a cultivar Guarani em cultivo irrigado por aspersão apresentou alto índice de acamamento, comparativamente às cultivares Carajás, Rio Paranaíba e Araguaia. Não houve diferenças entre as modalidades de preparo de solo na ausência de irrigação, já nos tratamentos irrigados o preparo com grade propiciou a obtenção dos menores índices de acamamento (Tabela 4). Quanto às lâminas de água dentro de preparo do solo, a lâmina 2 propiciou os maiores índices de acamamento, no preparo com grade.

Em relação ao número de panículas por metro quadrado, observa-se que as cultivares Carajás e Guarani apresentaram maiores valores do que a cultivar IAC 201, nos dois anos de experimentação (Tabela 2). Além disso, no ano agrícola 1997/98, em que houve a ocorrência de veranico, o tratamento sem irrigação propiciou a obtenção de menor número de panículas em relação ao tratamento irrigado com a lâmina 2 .

Quanto à massa de 100 grãos, verifica-se que a cultivar Guarani apresentou o maior valor, seguida pela Carajás e IAC 201, que apresentaram o menor valor nos dois anos agrícolas (Tabela 5). Esse comportamento era esperado, já que a IAC 201 apresen-

Tabela 4. Desdobramento da interação cultivar x lâmina de água e da interação preparo do solo x lâmina de água da análise de variância referente ao acamamento de plantas ${ }^{(1)}$.

\begin{tabular}{|c|c|c|c|}
\hline \multirow[t]{2}{*}{ Tratamento } & \multicolumn{3}{|c|}{ Irrigação $^{(2)}$} \\
\hline & Sem irrigação & Lâmina 1 & Lâmina 2 \\
\hline & \multicolumn{3}{|c|}{ Cultivar } \\
\hline IAC 201 & $0,35 \mathrm{bB}$ & $2,32 \mathrm{aA}$ & $3,15 \mathrm{aA}$ \\
\hline Carajás & $0,06 b$ & $0,00 \mathrm{~b}$ & $0,27 b$ \\
\hline \multirow[t]{2}{*}{ Guarani } & $0,86 \mathrm{aC}$ & $2,28 \mathrm{aB}$ & $4,05 \mathrm{aA}$ \\
\hline & \multicolumn{3}{|c|}{ Preparo do solo } \\
\hline Aiveca & $0,26 \mathrm{~B}$ & $2,14 \mathrm{aA}$ & $2,49 \mathrm{abA}$ \\
\hline Escarificador & $0,73 \mathrm{~B}$ & $1,85 \mathrm{aA}$ & $2,68 \mathrm{aA}$ \\
\hline Grade & $0,15 \mathrm{~B}$ & $0,30 \mathrm{bB}$ & $1,49 \mathrm{bA}$ \\
\hline \multicolumn{4}{|c|}{$\begin{array}{l}\text { (1)Médias seguidas de letras diferentes, minúsculas nas colunas e maiúscu- } \\
\text { las nas linhas, diferem estatisticamente entre si, pelo teste de Tukey a 5\% de } \\
\text { probabilidade; notas de acamamento: } 0 \text { : sem acamamento; } 1 \text { : até } 5 \% ; 2: 5 \text { a } \\
25 \% ; 3: 25 \text { a } 50 \% ; 4: 50 \text { a } 75 \% ; 5: 75 \text { a } 100 \% \text { de plantas acamadas. }{ }^{(2)} \text { Lâmi- } \\
\text { na 1: na fase vegetativa foi utilizado o coeficiente de cultura }(\mathrm{Kc}) \text { de } 0,2 ; \text { na } \\
\text { fase reprodutiva foi utilizado um Kc inicial de } 0,35 \text { e final de } 0,50 \text {; e na fase } \\
\text { de maturação, um Kc inicial de } 0,50 \text { e final de } 0,35 \text {; lâmina } 2 \text { : foi utilizado } \\
\text { o dobro dos valores de Kc para os mesmos períodos da lâmina } 1 \text {. }\end{array}$} \\
\hline
\end{tabular}


ta grãos longos e finos, do tipo agulhinha. Os resultados obtidos são concordantes com Arf et al. (2000). No que se refere ao preparo de solo, observa-se que no segundo ano de cultivo o preparo realizado com arado de aiveca propiciou a obtenção de menor valor para a massa de 100 grãos, comparativamente ao realizado com grade aradora. Talvez a explicação possa ser dada pelo número de grãos cheios por panícula em que teve o maior valor no preparo com arado de aiveca. Quanto às lâminas de água, o efeito foi marcante no primeiro ano de cultivo, no qual houve veranico na fase de florescimento e início do enchimento dos grãos. A maior massa de 100 grãos foi obtida na lâmina 2, seguida pela lâmina 1 e sem irrigação. Apesar de a massa de 100 grãos se constituir em caráter varietal bastante estável (Yoshida, 1981), houve influência do preparo do solo e das lâminas de água utilizadas.

Quanto ao peso hectolítrico, verifica-se que a cultivar Carajás apresentou maior peso hectolítrico, e as cultivares Guarani e IAC 201 apresentaram valores semelhantes nos dois anos de cultivo, concordando com Arf et al. (2000) (Tabela 5). Em relação ao preparo do solo, houve efeito significativo apenas no primeiro ano de cultivo, onde o escarificador propiciou a obtenção do maior valor de peso hectolítrico. No que se refere às lâminas de água, o resultado obtido nos dois anos de cultivo mostra que houve destaque para o tratamento em que se utilizou a lâmina 2 .

A cultivar Carajás destacou-se nos dois anos de cultivo, em relação à produção de grãos (Tabela 5). Os resultados obtidos são concordantes com Nakao

Tabela 5. Valores médios obtidos na avaliação do peso de 100 grãos, peso hectolítrico e produção de grãos de cultivares de arroz em terras altas em razão de diferentes sistemas de preparos de solo e lâminas de água aplicadas através de irrigação por aspersão. Selvíria, MS, 1997/98 e 1998/99(1).

\begin{tabular}{|c|c|c|c|c|c|c|}
\hline \multirow[t]{2}{*}{ Tratamento } & \multicolumn{2}{|c|}{$\begin{array}{l}\text { Massa de } 100 \text { grãos } \\
(\mathrm{g})\end{array}$} & \multicolumn{2}{|c|}{$\begin{array}{c}\text { Peso } \\
\text { hectolítrico }\end{array}$} & \multicolumn{2}{|c|}{$\begin{array}{l}\text { Produção de grãos } \\
\left(\mathrm{kg} \mathrm{ha}^{-1}\right)\end{array}$} \\
\hline & $97 / 98$ & $98 / 99$ & $97 / 98$ & $98 / 99$ & $97 / 98$ & $98 / 99$ \\
\hline \multicolumn{7}{|l|}{ Cultivar } \\
\hline IAC 201 & $2,25 \mathrm{c}$ & $2,31 \mathrm{c}$ & $50,23 b$ & $54,77 \mathrm{~b}$ & $3.055 \mathrm{~b}$ & $2.698 \mathrm{~b}$ \\
\hline Carajás & $2,88 b$ & $3,18 b$ & $56,09 \mathrm{a}$ & $60,23 \mathrm{a}$ & $3.463 \mathrm{a}$ & $3.627 \mathrm{a}$ \\
\hline Guarani & $3,23 \mathrm{a}$ & $3,44 \mathrm{a}$ & $50,77 \mathrm{~b}$ & $54,62 \mathrm{~b}$ & $3.003 \mathrm{~b}$ & $3.735 \mathrm{a}$ \\
\hline \multicolumn{7}{|l|}{ Preparo do solo } \\
\hline Aiveca & 2,79 & $2,94 b$ & $51,46 b$ & 56,29 & $3.275 \mathrm{a}$ & 3.419 \\
\hline Escarificador & 2,82 & $2,97 \mathrm{ab}$ & $53,80 \mathrm{a}$ & 56,23 & $3.490 \mathrm{a}$ & 3.362 \\
\hline Grade & 2,76 & $3,03 \mathrm{a}$ & $51,83 \mathrm{~b}$ & 57,11 & $2.756 \mathrm{~b}$ & 3.280 \\
\hline \multicolumn{7}{|l|}{ Irrigação $^{(2)}$} \\
\hline Sem irrigação & $2,56 \mathrm{c}$ & 2,96 & $50,71 \mathrm{~b}$ & $55,41 \mathrm{~b}$ & $1.614 \mathrm{c}$ & 3.381 \\
\hline Lâmina 1 & $2,78 b$ & 2,98 & $51,58 \mathrm{~b}$ & $56,33 b$ & $3.432 b$ & 3.368 \\
\hline Lâmina 2 & $3,02 \mathrm{a}$ & 3,00 & $54,81 \mathrm{a}$ & $57,89 \mathrm{a}$ & $4.475 \mathrm{a}$ & 3.311 \\
\hline \multicolumn{7}{|l|}{ Teste F } \\
\hline Cultivar (C) & $255,04 * *$ & $758,56 * *$ & $33,95 * *$ & $120,14 * *$ & $7,05 * *$ & $32,77 * *$ \\
\hline Preparo do solo (P) & $0,80^{\mathrm{ns}}$ & $4,82 *$ & $5,16 * *$ & $2,80^{\mathrm{ns}}$ & $15,84 * *$ & $0,49^{\mathrm{ns}}$ \\
\hline Lâmina de água (L) & $53,27 * *$ & $1,01^{\mathrm{ns}}$ & $15,09 * *$ & $18,56 * *$ & $233,20 * *$ & $0,14^{\mathrm{ns}}$ \\
\hline $\mathrm{C} \times \mathrm{P}$ & $0,13^{\mathrm{ns}}$ & $1,46^{\mathrm{ns}}$ & $2,37^{\text {ns }}$ & $0,99^{\text {ns }}$ & $1,52^{\mathrm{ns}}$ & $1,62^{\mathrm{ns}}$ \\
\hline $\mathrm{C} \times \mathrm{L}$ & $0,73^{\mathrm{ns}}$ & $1,61^{\mathrm{ns}}$ & $1,65^{\mathrm{ns}}$ & $1,21^{\mathrm{ns}}$ & $1,42^{\mathrm{ns}}$ & $0,28^{\mathrm{ns}}$ \\
\hline $\mathrm{P} \times \mathrm{L}$ & $1,04^{\mathrm{ns}}$ & $1,77^{\mathrm{ns}}$ & $1,46^{\mathrm{ns}}$ & $1,06^{\mathrm{ns}}$ & $3,19 *$ & $1,49^{\mathrm{ns}}$ \\
\hline $\mathrm{C} \times \mathrm{P} \times \mathrm{L}$ & $1,49^{\mathrm{ns}}$ & $0,56^{\mathrm{ns}}$ & $0,35^{\mathrm{ns}}$ & $0,99^{\mathrm{ns}}$ & $1,75^{\mathrm{ns}}$ & $0,59^{\mathrm{ns}}$ \\
\hline C.V. (\%) & 6,71 & 4,32 & 6,36 & 3,09 & 17,92 & 17,83 \\
\hline
\end{tabular}

(1)Médias seguidas de mesma letra dentro de cada parâmetro (cultivar, preparo do solo e lâmina de água não diferem entre si pelo teste de Tukey a $5 \%$ de probabilidade). (2)Lâmina 1: na fase vegetativa foi utilizado o coeficiente de cultura (Kc) de 0,2 ; na fase reprodutiva foi utilizado um Kc inicial de 0,35 e final de 0,50 ; e na fase de maturação, um Kc inicial de 0,50 e final de 0,35 ; lâmina 2 : foi utilizado o dobro dos valores de Kc para os mesmos períodos

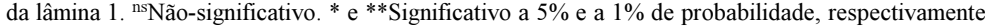


(1995) e Arf et al. (2000), que obtiveram maior produtividade na cultivar Carajás do que na IAC 201. Quanto ao preparo do solo, houve destaque no primeiro ano de cultivo para o arado de aiveca e escarificador, o que pode ser explicado pelo revolvimento mais profundo do solo nesses sistemas de preparo, permitindo que as plantas obtivessem água em camadas mais profundas uma vez que houve veranico durante a fase de florescimento e início de enchimento de grãos. Já no segundo ano de cultivo, como houve boa distribuição de chuvas, não houve diferenças significativas entre as modalidades de preparo utilizadas.

Quanto às lâminas de água, o efeito dos tratamentos foi bem marcante no primeiro ano de cultivo, pelas razões acima mencionadas (Tabela 5). As lâminas 1 e 2 propiciaram incrementos de produção de 113 e $177 \%$, respectivamente, em relação ao tratamento que recebeu água somente das chuvas. Oliveira (1994), também no Município de Selvíria, MS, obteve incrementos significativos na produção de grãos, porém variáveis entre as cultivares estudadas, sendo de 38, 75, 79 e 133\% nas cultivares Carajás, Araguaia, Caiapó e IAC 201, respectivamente. Santos (1990) obteve incremento de 90 e 35\%, respectivamente, para as cultivares Araguaia e Guarani, quando na presença de irrigação por aspersão em comparação com o sistema de sequeiro.

$\mathrm{O}$ desdobramento da interação preparo do solo $\mathrm{x}$ lâmina de água referente à produção de grãos no primeiro ano de cultivo (1997/98) está apresentado na Tabela 6. Pelos dados de preparo de solo dentro de lâminas de água, verifica-se que no tratamento

Tabela 6. Desdobramento da interação preparo de solo $x$ lâmina de água da análise de variância referente à produção de grãos $\left(\mathrm{kg} \mathrm{ha}^{-1}\right)^{(1)}$.

\begin{tabular}{lccc}
\hline Preparo do solo & \multicolumn{3}{c}{ Irrigação $^{(2)}$} \\
\cline { 2 - 4 } & Sem irrigação & \multicolumn{1}{c}{ Lâmina 1 } & \multicolumn{1}{c}{ Lâmina 2 } \\
\hline Aiveca & $1.395 \mathrm{bC}$ & $3.795 \mathrm{aB}$ & $4.635 \mathrm{aA}$ \\
Escarificador & $2.205 \mathrm{aC}$ & $3.457 \mathrm{abB}$ & $4.809 \mathrm{aA}$ \\
Grade & $1.242 \mathrm{bC}$ & $3.045 \mathrm{bB}$ & $3.981 \mathrm{bA}$ \\
\hline
\end{tabular}

${ }^{(1)}$ Médias seguidas de letras diferentes, minúsculas nas colunas e maiúsculas nas linhas, não diferem estatisticamente entre si, pelo teste de Tukey a 5\% de probabilidade. ${ }^{(2)}$ Lâmina 1: na fase vegetativa foi utilizado o coeficiente de cultura $(\mathrm{Kc})$ de 0,2 ; na fase reprodutiva foi utilizado um $\mathrm{Kc}$ inicial de 0,35 e final de 0,50 ; e na fase de maturação, um Kc inicial de 0,50 e final de 0,35 ; lâmina 2: foi utilizado o dobro dos valores de Kc para os mesmos períodos da lâmina 1 . sem irrigação houve destaque do preparo realizado com escarificador. Já nas lâminas 1 e 2 o destaque foi para o preparo realizado com arado de aiveca e escarificador, que na média apresentaram produtividade de aproximadamente 19\% superior ao preparo realizado com grade aradora. Talvez a explicação para o fato seja o maior volume de solo explorado pelo sistema radicular das plantas, no preparo realizado com arado de aiveca e escarificador em relação à grade aradora. Seguy et al. (1985), citados por Kluthcouski et al. (1988), verificaram que o enraizamento do arroz de sequeiro aumentou em $26 \%$ no perfil de 0 a $60 \mathrm{~cm}$, quando o solo sofreu descompactação nos primeiros $30 \mathrm{~cm}$. Observaram, ainda, que no preparo superficial contínuo, ou seja, compactado, que $85 \%$ das raízes encontravam-se nos primeiros $10 \mathrm{~cm}$, enquanto no solo descompactado foram observados apenas $51 \%$ do total. Quanto às lâminas de água dentro de preparo de solo, pode-se observar que em todas as modalidades de preparo do solo a produção de grãos é crescente, do tratamento de sequeiro ao tratamento onde se utilizou a lâmina 2.

\section{Conclusões}

1. O uso da irrigação suplementar por aspersão reduz o número de dias para florescimento e o ciclo da cultura em ano com ocorrência de veranico.

2. A cultivar Carajás apresenta maior produtividade de grãos e praticamente ausência de acamamento em relação às cultivares IAC 201 e Guarani, sob condições de irrigação por aspersão.

3. O preparo do solo com arado de aiveca ou escarificador propiciam a obtenção de maior produtividade de grãos em relação ao preparo com grade aradora em ano com presença de veranico.

4. A irrigação suplementar por aspersão propicia incremento de até $177 \%$ na produção de grãos de arroz, em ano com ocorrência de veranico.

\section{Agradecimentos}

Ao técnico agrícola Júlio Cesar dos Reis Pereira, bolsista da FAPESP, pela colaboração na instalação, condução, coleta de dados e análises em laboratório. 


\section{Referências}

ARF, O. Efeito de densidade populacional e adubação nitrogenada sobre o comportamento de cultivares de arroz irrigado por aspersão. Ilha Solteira : UNESP-FEIS, 1993. 63 p. Tese de Livre Docência.

ARF, O.; RODRIGUES, R. A. F.; SÁ, M. E.; CRUSCIOL, C. A. C. Influência da época de semeadura no comportamento de cultivares de arroz irrigado por aspersão em Selvíria, MS. Pesquisa Agropecuária Brasileira, Brasília, v. 35, n. 10, p. 1967-1976, out. 2000.

BAZONI, R.; COSTA, C. A.; ARF, O.; MORAIS, O. P.; SANTANA, E. P.; MOURA NETO, F. P.; PITOL, C. Recomendações de cultivares de arroz de sequeiro para o ano agrícola 1995/96, em Mato Grosso do Sul. Campo Grande : EMPAER-MS, 1995. 5 p. (EMPAER-MS. Comunicado Técnico, 17).

BRUNINI, O.; PEDRO JÚNIOR, M. J.; ALFONSI, R. R.; ORTOLANI, A. A. Eficiência do uso da água por cultivares de arroz em duas densidades de plantio. Bragantia, Campinas, v. 40, p. 135-143, 1981.

CARVALHO JÚNIOR, A. G. Efeito da adubação potássica em cultivares de arroz (Oryza sativa $L$.) de sequeiro sob déficit hídrico, em solos sob cerrado. Lavras : ESAL, 1987. 165 p. Dissertação de Mestrado.

CASTRO, O. M.; VIEIRA, S. R.; MARIA, I. C. Sistema de preparo do solo e disponibilidade de água. In: SIMPÓSIO SOBRE O MANEJO DE ÁGUA NA AGRICUlTURA, 1987, Campinas. Anais... Campinas : Fundação Cargill, 1987. p. 27-51.

CRUSCIOL, C. A. C. Espaçamento e densidade de semeadura do arroz, cv. IAC 201, sob condições de sequeiro e irrigado por aspersão. Botucatu : UNESP, 1995. 104 p. Dissertação de Mestrado.

DOORENBOS, J.; KASSAN, A. H. Efectos del agua en el rendimiento de los cultivos. Roma: FAO, 1979. 212 p. (Estudios FAO. Riego y Drenaje, 33).

DOORENBOS, J.; PRUITT, W. O. Las necesidades de agua de los cultivos. Roma : FAO, 1976. 194 p. (Estudios FAO. Riego e Drenaje, 24)

GROHMANN, F. Distribuição e tamanho de poros em três tipos de solos do Estado de São Paulo. Bragantia, Campinas, v. 21, n. 18, p. 285-295, 1960.

KLUTHCOUSKI, J.; BOUZINAC, S.; SEGUY, L. Preparo do solo. In: ZIMMERMANN, M. J.; ROCHA, M.; YAMADA, T. (Ed.). Cultura do feijoeiro: fatores que afetam a produtividade. Piracicaba : Associação Brasileira para Pesquisa da Potassa e do Fosfato, 1988. p. 249-259.
NAKAO, W. S. Manejo de água na cultura do arroz (Oryza sativa L.) irrigado por aspersão. Ilha Solteira : UNESP-FEIS, 1995. 44 p.

OLIVEIRA, G. S. Efeito de densidade de semeadura no desenvolvimento de cultivares de arroz (Oryza sativa $\mathrm{L}$.) em condições de sequeiro irrigado por aspersão. Ilha Solteira : UNESP-FEIS, 1994. 41 p.

OLIVEIRA, I. P.; KLUTHCOUSKI, J.; YOKOYAMA, L. P.; DUTRA, L. G.; PORTES, T. A.; SILVA, A. E.; PINHEIRO, B. S.; FERREIRA, E.; CASTRO, E. M.; GUIMARÃES, C. M.; GOMIDE, J. C.; BALBINO, L. C. Sistema Barreirão: recuperação/renovação de pastagens degradadas em consórcio com culturas anuais. Goiânia : Embrapa-CNPAF, 1996. 90 p. (Embrapa-CNPAF. Documentos, 64)

PEDROSO, P. A. C.; CORSINI, P. C. Manejo físico do solo. In: FERREIRA, M. E.; YAMADA, T.; MALAVOLTA, E. Cultura do arroz de sequeiro: fatores afetando a produtividade. Piracicaba: Associação Brasileira para a Pesquisa da Potassa e do Fosfato, 1983. p. 225-238.

RAIJ, B. van; QUAGGIO, J. A. Métodos de análise de solo para fins de fertilidade. Campinas : Instituto Agronômico, 1983. 31 p. (IAC. Boletim Técnico, 81).

RAIJ, B. van; CANTARELLA, H.; QUAGGIO, J. A.; FURLANI, A. M. C. Recomendações de adubação e calagem para o Estado de São Paulo. 2. ed. Campinas : Instituto Agronômico, 1996. 285 p. (IAC. Boletim Técnico, 100).

RICHARDS, L. A. Pressure membrane apparatus construction and use. Agricultural Engineering, St. Joseph, v. 28, p. 451-454, 1947.

RICHARDS, L. A.; FIREMAN, M. Pressure-plate apparatus for measuring moisture sorting and transmission by soils. Soil Science, Baltimore, v. 56, p. 395-404, 1943.

SANTOS, A. B. Comportamento de cultivares de arroz de sequeiro em diferentes populações de plantas com e sem irrigação suplementar. Piracicaba : USP, 1990. 94 p. Tese de Doutorado.

STONE, L. F.; LIBARDI, P. L.; REICHARDT, K. Produtividade do arroz e absorção de nitrogênio afetadas pelo veranico e pela adição de vermiculita ao solo. Pesquisa Agropecuária Brasileira, Brasília, v. 21, n. 2, p. 117-125, fev. 1986.

YOSHIDA, S. Growth and development of the rice plant. In: Fundamentals of rice crop science. Los Baños : International Rice Research Institute, 1981. p. 1-63. 